$11-15$ years $(51.0 \%)$, followed by 16 years and older $(31.1 \%)$. The most common hearing complaint was hearing loss $(27.4 \%)$, followed by otalgy $(17.9 \%)$ and tinnitus (16.0\%). The occurrence of suppurative otitis media was related by $12.3 \%$ of patients and $18.9 \%$ presented tympanic membrane perforation at the time of hearing evaluation. Patients with hearing loss had higher prevalence of hearing complaints than those with normal hearing: otorrhoea $(92.9 \% \times 7.1 \% ; p<0.001)$, tinnitus $(76.5 \% \times 23,5 \% ; p<0.001)$, otalgy $(68.4 \% \times 31.6 \% ; p=0.001)$ and sensation of fullness in the ear $(61.5 \% \times 38.5 \% ; \mathrm{p}=0.039)$. There was no difference according to dizziness $(36.4 \% \times 63.6 \% ; \mathrm{p}=0.970)$.

Conclusion It is extremely important to precociously detect, evaluate and observe any hearing complaints that these patients may present. These are important signs that if detected and treated early, can avoid serious consequences like hearing loss.

\section{P2-283 BREAST CANCER DATA QUALITY AT THE POPULATION- BASED CANCER REGISTRY OF SãO PAULO: IMPLICATIONS FOR PUBLIC HEALTH SURVEILLANCE AND PLANNING}

doi:10.1136/jech.2011.142976k.16

\begin{abstract}
1,2D Silveira, ${ }^{*}$ E Artmann. ${ }^{1}$ Fundação Oswaldo Cruz - Fiocruz, Escola Nacional de Saúde Pública, Rio de Janeiro, Rio de Janeiro, Brazil; ${ }^{2}$ Agência Nacional de Saúde Suplementar - Ans, Rio de Janeiro, Rio de Janeiro, Brazil
\end{abstract}

Cancer affects millions of people each year worldwide and represents a major challenge for healthcare systems. Information based on populational data, such as Cancer Registries, are essential to endorse health planning and provision of cancer care services. This paper aims to present a data quality evaluation of breast cancer incidence data from the Population Based Cancer Registry of the Municipality of São Paulo, Brazil. The study included 46311 new breast cancer cases recorded during a two 5-year periods (1997-2001 and 2002-2006). Data analysis was focused on variables such as: date and age at diagnosis, clinical stage, topographic distribution and tumour morphology. For women aged between 40 and 69 years, the most common diagnosis was the malignant neoplasm of breast, unspecified (ICD-10 C50.9), (87,6\% of all cases), which does not specify clearly the topography and extent of disease. Problems of information completeness for important variables such as clinical and pathological staging were identified on time-series analysis. Hence, data quality of cancer registries are crucial for breast cancer survival analysis as well as for planning cancer control policies, enhancements on data collection are required.

\section{P2-284 THE IMPACT OF THE PAY-FOR-PERFORMANCE CONTRACT AND THE MANAGEMENT OF HYPERTENSION IN SCOTTISH PRIMARY CARE: A SIX-YEAR POPULATION-BASED REPEATED CROSS-SECTIONAL STUDY}

doi:10.1136/jech.2011.142976k.17

${ }^{1} \mathrm{C}$ Simpson, ${ }^{*} \mathrm{P}$ Hannaford, ${ }^{2} \mathrm{~L}$ Ritchie, ${ }^{1} \mathrm{~A}$ Sheikh, ${ }^{3} \mathrm{D}$ Williams. ${ }^{1}$ The University of Edinburgh, Edinburgh, UK; ${ }^{2}$ The University of Aberdeen, Aberdeen, UK; ${ }^{3}$ Royal College of Surgeons of Ireland, Dublin, Ireland

Background The introduction of pay-for-performance (in 2004) has increased the proportion of income general practitioners are able to earn from targeted quality care to patients with chronic diseases such as hypertension. We wished to investigate the impact of payfor-performance on the management of patients with hypertension in Scottish primary care.
Method A population-based repeated cross-sectional study using data from 826973 patients registered with 315 Scottish primary care practices. Information was extracted on age, sex, socioeconomic deprivation, hypertension diagnosis, recorded blood pressure measurement, attainment of target blood pressure levels and provision of hypertension-related prescribing for each year for the period 2001-2006.

Results Increasing treatment for hypertension (Absolute Difference (AD): $9.2 \%$; $95 \%$ CI 9.0 to 9.5) was found. The majority of increases in blood pressure measurement (AD: $46.8 \%$; 95\% CI 46.5 to 47.1 ) and recorded hypertension (AD: $5.9 \%$; $95 \%$ CI 5.7 to 6.0 ) occurred prior to 2004. Blood pressure control increased throughout the study period (absolute increase =140/90 mm Hg: 18.9\%; 95\% CI 18.5 to 19.4). After 2004, the oldest female and most socioeconomically deprived male and female patients became less likely than their youngest ( $<40$ years) and most affluent counterparts to have a blood pressure measurement recorded $(p<0.05)$. Patients not prescribed therapy were younger and had higher blood pressure levels $(p<0.001)$

Conclusions It is likely that the continued efforts of general practice to improve hypertension diagnosis, monitoring and treatment will reduce future cardiovascular events and deaths in this population. However, there is a need to follow-up older and more socioeconomically deprived patients once they are diagnosed and prescribe anti-hypertensive therapy to younger patients who are likely to benefit from early intervention.

\section{P2-285 ENVIRONMENTAL CADMIUM EXPOSURE AND BLOOD PRESSURE IN THE GENERAL POPULATION}

doi:10.1136/jech.2011.142976k.18

${ }^{1} \mathrm{~J}$ Sirivarasai, ${ }^{* 1} \mathrm{~S}$ Kaojarern, ${ }^{2} \mathrm{~S}$ Chansirikarnjana, ${ }^{3} \mathrm{~T}$ Sura, ${ }^{3} \mathrm{O}$ Krairit, ${ }^{4} \mathrm{R}$ Chunhabundit, ${ }^{5} \mathrm{~S}$ Chanprasertyothin, ${ }^{6} \mathrm{~S}$ Chotvitayataragorn, ${ }^{7} \mathrm{~W}$ Prasanatikom. ${ }^{1}$ Division of Clinical Pharmacology and Toxicology, Faculty of Medicine, Ramathibodi Hospital, Mahidol University, Bangkok, Thailand; '2Division of Geriatric Medicine, Bangkok, Thailand; ${ }^{3}$ Division of Medical Genetics, Bangkok, Thailand; ${ }^{4}$ Graduate Program in Nutrition, Bangkok, Thailand; ${ }^{5}$ Research Center, Bangkok, Thailand; ${ }^{6}$ Health Promotion Unit, Bangkok, Thailand; ${ }^{7}$ Ambulatory Nursing Care Service Unit, Bangkok, Thailand

Introduction Animal studies have been shown a positive association between high dose cadmium exposure and blood pressure. However, effect of low-level cadmium exposure that typically found in the general population is reported in a few studies. Thus, the objective of this study was to examine the relationship between blood cadmium levels and blood pressure in a non-occupationally exposed population.

Methods The subjects consisted of 500 women and 126 men (age range 40-60) in which blood pressure and blood cadmium were measured. Blood cadmium was determined by GFAAS.

Results The geometric mean of blood cadmium was $0.91 \mu \mathrm{g} / \mathrm{l}$. The prevalence of hypertension was $13.9 \%$. Among all participants, positive relationships were seen between both systolic and diastolic blood pressure and blood cadmium levels $(p<0.05)$. Analysis in subgroup found that cadmium levels increased with cigarette smoking rate among current smokers $(p=0.04)$. The results of stepwise multiple regression showed that systolic and diastolic blood pressure were significantly correlated with age, body mass index, smoking cigarette and blood cadmium level.

Conclusion The present data provide some support for a causal association between cadmium exposure and increased blood pressure. However, genetic susceptibility and duration of exposure could also be important determinants of these responses to cadmium exposure. 